\title{
Effects of Strength Training versus Power Training on Physical Performance in Prefrail Community-Dwelling Older Adults
}

\author{
Michael Drey ${ }^{a}$ Astrid Zech ${ }^{e}$ Ellen Freiberger ${ }^{b}$ Thomas Bertsch ${ }^{d}$ \\ Wolfgang Uter ${ }^{c}$ Cornel C. Sieber ${ }^{a}$ Klaus Pfeifer ${ }^{b}$ Juergen M. Bauer ${ }^{f}$

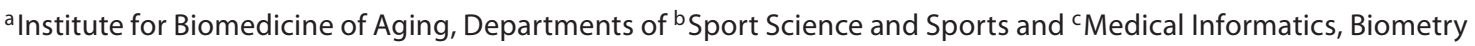 \\ and Epidemiology, University of Erlangen-Nuremberg, and d Laboratory Medicine and Transfusion Medicine, \\ Institute for Clinical Chemistry, Klinikum Nuremberg, Nuremberg, ${ }^{e}$ Department of Movement Science, University of \\ Hamburg, Hamburg, and ${ }^{\mathrm{f}}$ Geriatric Center Oldenburg, Klinikum Oldenburg, Oldenburg, Germany
}

\section{Key Words}

Strength training $\cdot$ Power training $\cdot$ Frailty $\cdot$ Vitamin D

\begin{abstract}
Background: It has been unclear which training mode is most effective and feasible for improving physical performance in the risk group of prefrail community-dwelling older adults. Objective: The purpose of the present study was to compare the effects of strength training (ST) versus power training (PT) on functional performance in prefrail older adults. This study was registered at clinicaltrials.gov as NCT00783159. Methods: 69 community-dwelling older adults ( $>65$ years) who were prefrail according to the definition of Fried were included in a 12-week exercise program. The participants were randomized into an ST group, a PT group and a control group. All participants were supplemented with vitamin $D_{3}$ orally before entering the intervention period. The primary outcome was the global score on the Short Physical Performance Battery (SPPB). Secondary outcomes were muscle power, appendicular lean mass (aLM) measured by dual energy X-ray absorptiometry and self-reported functional deficits (Short Form of the Late-Life Func-
\end{abstract}

tion and Disability Instrument, SF-LLFDI). Results: Regarding changes in the SPPB score during the intervention, significant heterogeneity between the groups was observed ( $p=$ 0.023). In pair-wise comparisons, participants in both training groups significantly (PT: $p=0.012, \mathrm{ST}$ : 0.009 ) increased their SPPB score (PT: $\Delta_{\text {mean }}=0.8, \mathrm{ST}: \Delta_{\text {mean }}=1.0$ ) compared to the control group, with no statistical difference among training groups $(p=0.301)$. No statistical differences were found in changes in aLM ( $p=0.769)$, muscle power $(p=$ $0.308)$ and SF-LLFDI $(p=0.623)$ between the groups. Muscle power significantly increased $(p=0.017)$ under vitamin $D_{3}$ intake. Conclusions: In prefrail community-dwelling adults, PT is not superior to ST, although both training modes resulted in significant improvements in physical performance. With regard to dropout rates, ST appears to be advantageous compared to PT. The high prevalence of vitamin $D_{3}$ deficiency and the slight improvement of physical performance under vitamin $D_{3}$ supplementation among study participants underline the relevance of this approach in physical exercise interventions.

Copyright $\odot 2011$ S. Karger AG, Basel

\section{KARGER}

Fax +4161306 1234

E-Mail karger@karger.ch

www.karger.com
(C) 2011 S. Karger AG, Basel

0304-324X/12/0583-0197\$38.00/0

Accessible online at:

www.karger.com/ger
Michael Drey, MD

Institute for Biomedicine of Aging, University of Erlangen-Nuremberg

Heimerichstrasse 58

DE-90419 Nuremberg (Germany)

Tel. +49911300 050, E-Mail michael.drey@gmx.de 


\section{Introduction}

Daily activities like walking, stair climbing and chair rising require muscle strength. Numerous studies have shown that although strength training (ST) benefits muscle strength in older adults, it only exerts a small to moderate effect on physical performance [1]. In recent years, a variety of studies indicated that muscle power (generation of muscular work per unit of time or, in other words, the product of force and velocity of muscle contraction) is more closely related to physical performance than muscle strength [2-6]. The core element of the power training (PT) concept is that the concentric part (lifting or pushing) of ST has to be completed as fast as possible whereas the eccentric part (lowering) has to be completed in approximately 2-3 s [7-9]. Studies published until now that compared the effects of ST and PT on physical performance in older adults have shown inconsistent results [713]. The latest review on this topic found a small advantage for PT [14].

In none of the aforementioned studies was vitamin $\mathrm{D}_{3}$ deficiency accounted for, nor was the outcome controlled for $25-\mathrm{OH}-\mathrm{D}_{3}$ serum level. Randomized controlled trials that investigated the effects of vitamin D supplementation on physical performance in older adults have shown a clear tendency towards improvement in muscle strength and physical performance [15-18]. Considering the high prevalence of vitamin D deficiency in older adults, vitamin D supplementation in the cohort to be studied should confirm this fact.

The present study compared the effects of ST and PT on physical performance, muscle power, appendicular lean mass (aLM) and self-reported functional deficits in prefrail older adults that were supplemented with vitamin $\mathrm{D}_{3}$ before the start of the training period.

\section{Method}

Design

This study was a randomized, controlled, single-blind 12week intervention study to determine the effects of PT and ST on physical performance, sit-to-stand transfer power, aLM and selfreported functional deficit in prefrail older adults according to the definition of Fried et al. [19]. During the run-in phase, before the intervention period, all participants started taking vitamin $D_{3}$ supplements. The time line of the trial is shown in figure 1 . The study was approved by the Medical Ethics Committee of the local University and registered at clinicaltrials.gov as NCT00783159.

\section{Participants}

As mentioned above, the participants were selected as prefrail according to the definition of Fried et al. [19] because prefrail individuals are regarded as a risk group with regard to functional decline and, therefore, they constitute a suitable target group for intervention studies aiming to stabilize or improve physical performance [20,21]. Considering the aging societies and limited financial resources in the health care systems, it will become increasingly important to focus interventional trials on risk groups like prefrail older adults. In this study, independent communitydwelling older adults, aged 65-94 years were recruited by advertising in newspapers, by direct mailings in cooperation with a local insurance company, in facilities of assisted living and through the database of the local geriatric day clinic, resulting in an assessment for eligibility of 663 subjects [22]. Of these, 365 persons met at least one exclusion criterion, whereas 298 were identified as potentially eligible and attended a screening session for prefrailty (fig. 2). Exclusion criteria were depression (GDS $>5$ ), dementia (MMSE <25), BMI $>35 \mathrm{~kg} / \mathrm{m}^{2}$, intake of immunosuppressive drugs, history of kidney stones, sarcoidosis, plasmacytoma, COPD, inflammatory bowel disease, angina pectoris, history of cancer and current attendance of muscle training. After providing informed consent, potentially eligible participants underwent a frailty screening. The frailty score of Fried et al. [19] comprises a possible range from 0 to 5 . Older persons who fulfilled one or two of the criteria were categorized as prefrail and thus considered as eligible. The original criteria applied were:

(1) Unintentional Weight Loss. Participants scored positive when reporting unintentional weight loss of more than $10 \mathrm{lb}$ during the last year.

(2) Self-Reported Exhaustion. Two items from the Center for Epidemiologic Studies-Depression Scale (CES-D scale) [19] were used to evaluate exhaustion.

(3) Weakness. Hand grip strength was measured using a handheld dynamometer (Jamar, USA). The greater mean value of three measurements of each hand was the relevant parameter for evaluating this criterion. The original cut-offs set by Fried et al. [19], stratified by BMI and gender, were used.

(4) Slow Walking Speed. Assessment of time for walking a $15-\mathrm{ft}$ distance at the usual pace, with or without a walking aid, was performed. The original stratified cut-offs (gender and body height) were used to score this criterion.

(5) Low Physical Activity Level. Based on the Minnesota Leisure Time Physical Activity Questionnaire (MLTPAQ) [19], the subjects were asked how much time they spent on 18 different tasks within the last 2 weeks; the results were converted into kilocalories to evaluate this criterion. The original cut-offs set by Fried et al. [19], stratified by gender, were used.

Among the 298 persons screened, 182 turned out not to be prefrail. Forty-seven prefrail participants rejected participation. After vitamin $\mathrm{D}_{3}$ saturation, 69 participants were stratified by sex and randomized into the ST group $(\mathrm{n}=23)$, the PT group $(\mathrm{n}=24)$ and the control group $(n=22)$ (fig. 2$)$. Randomization was computer-generated in blocks of 12-15 participants by a study collaborator not involved in other pars of the study. Sealed envelopes with group assignment were handed out to each participant by the blinded assessor.

\section{Vitamin D Supplementation}

At baseline $\left(\mathrm{T}_{0}\right)$ and after a run-in phase of 8 weeks $\left(\mathrm{T}_{1}\right), 25$ $\mathrm{OH}-\mathrm{D}_{3}$ serum levels were analyzed in a fasting state. Analyses were done with an immunoassay from Roche Diagnostics (Mannheim, Germany) and verified on an Agilent 1100 ChemStation (Wald- 
Fig. 1. Study timeline.

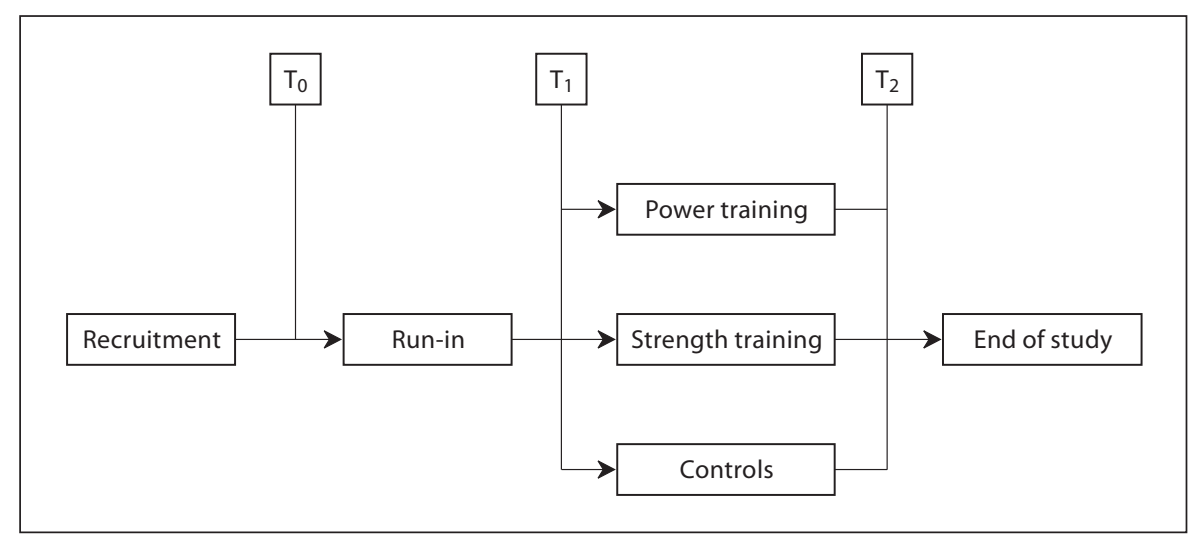

Fig. 2. Consort participant flow diagram.

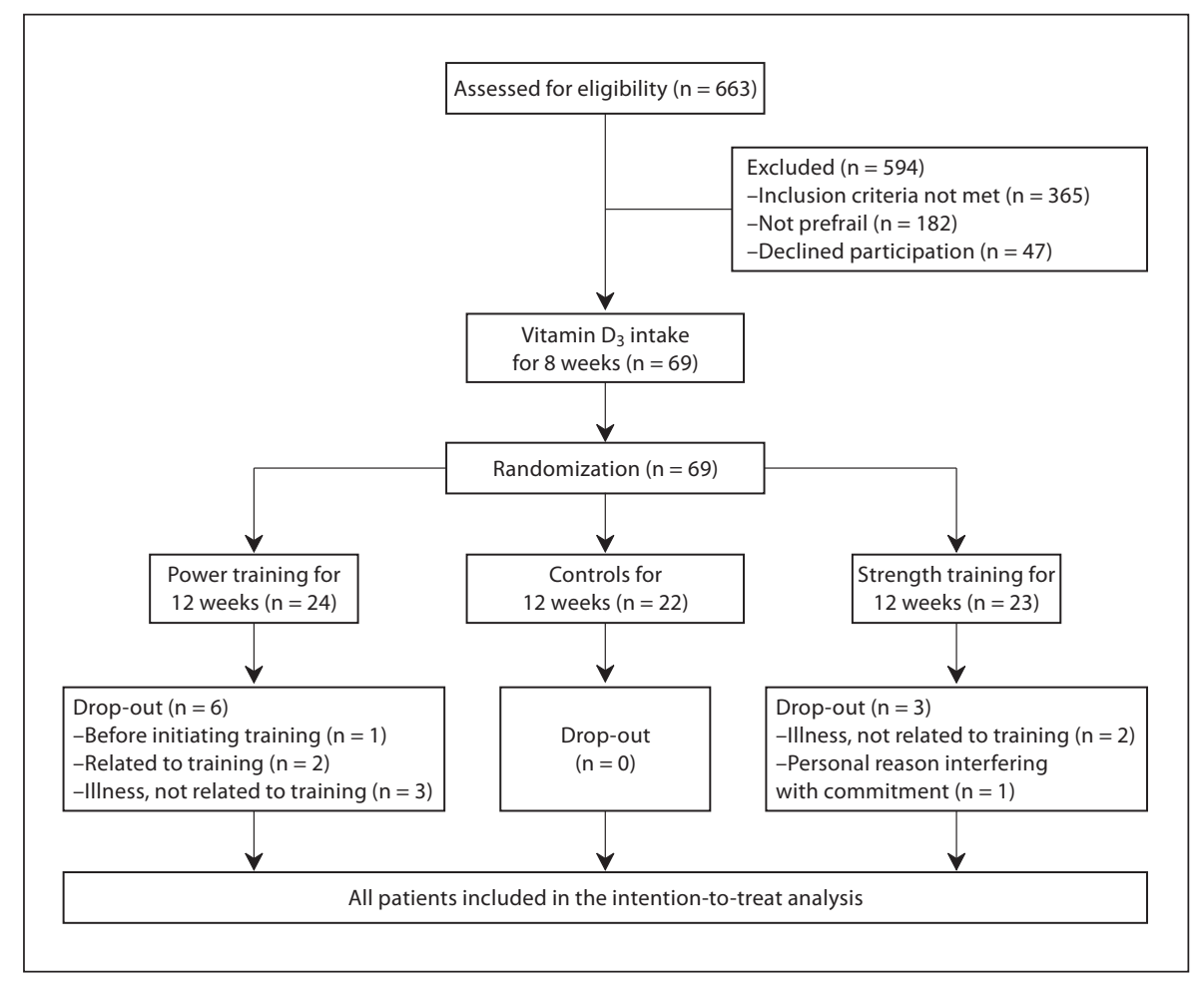

bronn, Germany) by an HPLC technique with a kit from Chromsystems (München, Germany) according to the manufacturer's instructions. Based on the serum levels at $\mathrm{T}_{0}$, participants were provided with vitamin $\mathrm{D}_{3}$ orally. Participants with levels greater than $20 \mathrm{ng} / \mathrm{ml}$ received 1,000 IU per day and participants whose levels were less received 2,000 IU per day throughout the whole study.

\section{Training Protocol}

The training program started immediately after the run-in phase of vitamin $\mathrm{D}_{3}$ intake. Both training groups began with a 5-min warm-up program of walking exercises, followed by a 20 min balance exercise program performed on the floor, on mats and on wobble boards in combination with ball-catching exer- cises. All training sessions were supervised by trained instructors and the compliance was recorded by using exercise diaries. Participants trained 2 days a week for 12 weeks using the 'Bodyspider' resistance training machine (KOOPERA, Germany). This machine works with elastic bands producing the loads. The loading characteristic is almost linear along the movement. Each training session lasted $60 \mathrm{~min}$.

After the warm-up and balance program, the PT group performed explosive resistance training. They were instructed to move as rapidly as possible during the concentric part of each repetition and to move slowly during each eccentric part (approximately 2-3 s). To ensure the required movement velocity, the participants were verbally encouraged. 
The ST group followed the same routine as the PT group, but performed the concentric and eccentric contractions with an 'average' velocity (2-3 s). Both intervention groups completed two sets with 2 min rest between each set. The training intensity was augmented every fortnight by improving tensile strength (Borg's Rate of Perceived Exertion (RPE) [23] to 10-11 in the first weeks, Borg's RPE to 16 in the final weeks) and reducing repetitions (15 repetitions in the first weeks, 6 repetitions in the final weeks) according to the guidelines of McDermott and Mernitz [24]. The exercises in the PT and ST groups were as follows: chest press, hip extension/flexion while standing, hip adduction/abduction while standing, tip-toe raises and chair rise. All exercises except the last two were performed on the resistance training machine. The tiptoe and chair rise movements were performed without weights with maximum repetition. Both exercises included an explosive concentric phase in the PT group (fast speed) and normal speed in the ST group.

All study members (including the control group) were instructed to maintain their current level of physical activity throughout the study period. During the intervention phase, the control group was invited for two lectures about physical activity and healthy nutrition. To improve compliance, the control group was offered to participate in a combined ST and PT program of 12 weeks after the end of the study.

\section{Outcome Measures}

Primary Outcome

Physical performance was measured using the score on the Short Physical Performance Battery (SPPB) established by Guralnik et al. [25]. SPPB is a well-established, reliable and valid measure of lower extremity performance that is predictive of adverse health outcomes like morbidity, institutionalization and mortality $[26,27]$. The score comprises assessment of standing balance, timed 4-meter walk and timed test of 5 chair rise repetitions. The global score ranges from 0 (low performance) to 12 points (high performance) and was measured at baseline, before and after the training intervention.

Secondary Outcome

Muscular power of the lower limb was tested by the sit-tostand transfer test described by Lindemann et al. [28] and was measured at baseline, before and after the training intervention. Participants were seated on the front part of a chair (height: 49 $\mathrm{cm}$ ) with arms crossed over chest, eyes fixed straight ahead and both feet on a force plate (Zebris Medical, Germany). They were then asked to rise as fast as possible into a standing position and to stand as quiet as possible until the end of data recording. The test was performed three times with a 1-min rest between the trials. During all trials, the participants were verbally encouraged by the investigator to ensure the explosive movement. Sit-to-stand transfer power (STS-power) is defined as $\mathrm{P}=\mathrm{F} \cdot \mathrm{s} / \mathrm{t}$ and was calculated by using the changes in vertical ground reaction force (collected at $558 \mathrm{~Hz}$ ) during the rising phase (t:time in seconds between peak force and end of the rising phase), vertical ground reaction force during quiet standing $(\mathrm{F}=\mathrm{m} \cdot \mathrm{g}, \mathrm{m}$ : weight of subject in $\mathrm{kg}, g: 9.81 \mathrm{~m} / \mathrm{s}^{2}$ ) and the difference between body height standing and body height sitting in meters (s). The trial that showed the highest power was used for analysis.

Besides objective performance tests, one self-report measure of function, the Short Form of the Late Life Function and Disabil- ity Instrument (SF-LLFDI function component, German version) was used. It was documented at the beginning and at the end of the training intervention [29]. The function component assesses advanced lower extremity function, basic lower extremity function, and upper extremity function. It has been regarded as a reliable and valid measure in older adults $[30,31]$. The score was documented as individual points out of 100 .

Body composition was assessed using a dual energy X-ray absorptiometry (DXA) scanner (Lunar Prodigy, GE Healthcare Technologies, USA). aLM was calculated as the sum of the lean mass of both arms and legs, and was measured before and after the training intervention. For aLM, Cronbach's $\alpha$ for repeated measures on a subsample of 20 participants was 0.998 .

\section{Statistical Analysis}

In view of the partly ordinal outcomes, and of the mostly skewed, nonnormal distribution of the metric outcomes, nonparametric statistical test methods were used throughout. Outcome values are shown as means and medians including upper and lower quartile. The Wilcoxon signed rank test was used to determine the effects of vitamin $\mathrm{D}_{3}$ saturation. Group differences before training were statistically examined with the KruskalWallis test. For the training intervention, the Kruskal-Wallis test for statistical testing of heterogeneity of pre- and posttraining differences among groups was used. In case of significance, the Mann-Whitney U test was used for a post hoc pair-wise test. The level of significance was set at 5\%. Exact $p$ values of the abovementioned nonparametric tests were approximated by Monte Carlo simulation, supplemented with a $99 \%$ confidence interval (CI). The evaluation is based on an intention-to-treat analysis. Missing data were replaced by 'last value carried forward'. No relevant difference was noted between a supplemental per protocol and the intention-to-treat analysis. The statistical analysis was performed using PASW 19.0 (IBM-SPSS Inc., Chicago, Ill., USA).

\section{Results}

\section{Participants}

Of 69 participants, 9 (control: 0, ST: 3 (13\%), PT: 6 (25\%)) did not complete the study. The reasons for droping out included medical and personal reasons (fig. 2). Two participants left the PT group because of adverse events during training (exacerbation of osteoarthritis, vertigo). No participant left the ST group for reasons related to the training mode. Table 1 shows the characteristics of the participants in each group. No statistical group differences were identified.

\section{Outcome Parameters}

Table 2 shows the $25-\mathrm{OH}-\mathrm{D}_{3}$ serum level, SPPB score and STS-Power at baseline $\left(\mathrm{T}_{0}\right)$ and 8 weeks after vitamin $\mathrm{D}_{3}$ supplementation $\left(\mathrm{T}_{1}\right)$. At baseline, about $80 \%$ of the participants had levels below $30 \mathrm{ng} / \mathrm{ml}$ (data not shown). 
Table 1. Characteristics of participants $\left[\right.$ mean/median $\left.\left(\mathrm{Q}_{1}-\mathrm{Q}_{3}\right)\right]$ and corresponding Monte-Carlo estimate of the p value with $99 \%$ CI for the Kruskal-Wallis test and the Mann-Whitney U test

\begin{tabular}{lllll}
\hline & Control & PT & ST & p value, 99\% CI \\
\hline Age, years & $76 / 76(70-82)$ & $78 / 77(73-84)$ & $77 / 77(72-80)$ & $0.501,0.488-0.514$ \\
Female, \% & 73 & 67 & 70 & $0.948,0.942-0.954$ \\
BMI, kg/m ${ }^{2}$ & $28 / 28(25-31)$ & $28 / 27(25-31)$ & $30 / 29(26-33)$ & $0.513,0.500-0.526$ \\
Attendance, \% & - & $68 / 88(25-96)$ & $80 / 92(83-96)$ & $0.076,0.069-0.083$ \\
\hline
\end{tabular}

Figures in parentheses are lower and upper quartile.

Table 2. Mean/median $\left(\mathrm{Q}_{1}-\mathrm{Q}_{3}\right)$ and corresponding Monte-Carlo estimate of the $\mathrm{p}$ value for the Wilcoxon signed rank test with $99 \%$ CI

\begin{tabular}{lcccc}
\hline & $\mathrm{T}_{0}$ & $\mathrm{~T}_{1}$ & $\mathrm{~T}_{1}-\mathrm{T}_{0}$ & $\mathrm{p}$ value, 99\% CI \\
\hline 25-OH-D, $\mathrm{ng} / \mathrm{ml}$ & $22 / 20(13-29)$ & $36 / 36(31-39)$ & $13 / 13(4-23)$ & $0.000,0.000-0.000$ \\
SPPB, points & $9 / 9(7-11)$ & $9 / 10(8-11)$ & $0 / 0(-1$ to 1$)$ & $0.065,0.058-0.071$ \\
Power, W & $458 / 428(387-537)$ & $475 / 454(330-584)$ & $27 / 18(-26$ to 76$)$ & $0.017,0.013-0.020$
\end{tabular}

Figures in parentheses are lower and upper quartile. $\mathrm{T}_{0}=$ Baseline; $\mathrm{T}_{1}=$ end of run-in-phase.

$25-\mathrm{OH}-\mathrm{D}_{3}$ level rose significantly to $36 \mathrm{ng} / \mathrm{ml}$ after 8 weeks of supplementation. No significant change was observed in the SPPB score, whereas the STS-Power increased significantly during the run-in phase.

Table 3 shows the values of the outcome parameters before $\left(\mathrm{T}_{1}\right)$ and after the 12-week intervention $\left(\mathrm{T}_{2}\right)$. No statistical group differences were detected at $\mathrm{T}_{1}$. Statistical heterogeneity of the difference $T_{2}-T_{1}$ was found for the SPPB score. Post hoc pair-wise tests for the SPPB score showed significant differences between $\mathrm{PT}$ and control and between ST and control (PT: $\Delta_{\text {mean }}=0.8, \mathrm{ST}: \Delta_{\text {mean }}=$ 1.0). No difference was detected between PT and ST. No statistical heterogeneity of the difference $T_{2}-T_{1}$ was found for muscle power, aLM and SF-LLFDI.

\section{Discussion}

ST and PT both resulted in significant improvements in physical performance in prefrail community-dwelling older adults. No statistical difference was found between the two training modes.

Our results are partly in line with other studies that have compared the effects of PT and ST in older adults [7-13]. Although in each of the aforementioned studies, muscle power was examined, physical performance was measured in only 5 studies as an outcome parameter [7, $8,10,12,13]$. Choosing muscular power instead of physical performance as the primary outcome is plausible as several cross-sectional studies have shown a strong relationship between muscular power and physical performance $[32,33]$. However, it cannot be concluded either from the present study or from other intervention studies that exercise resulting in improvements in muscular power will be accompanied by an improvement in physical performance $[10,13]$. In only 1 study [12] was the increase in power paralleled by an improvement in physical performance. Physical function, as evaluated by the SPPB score, is a strong predictor of morbidity, institutionalization and mortality $[26,27]$, while this relationship is still unclear for muscular power [34]. Until now, only 1 study could show that improvements in leg power contributed to a clinically meaningful improvement in the SPPB score and gait speed independently of strength [35]. Therefore, physical performance should be used as a primary outcome. Furthermore, data are available on meaningful changes in physical performance measured by the SPPB. Changes of about 1.0 point on the SPPB scale in our study are commonly regarded as a substantial change [36, 37]. Observational data have shown that a 1-year decline of 1 


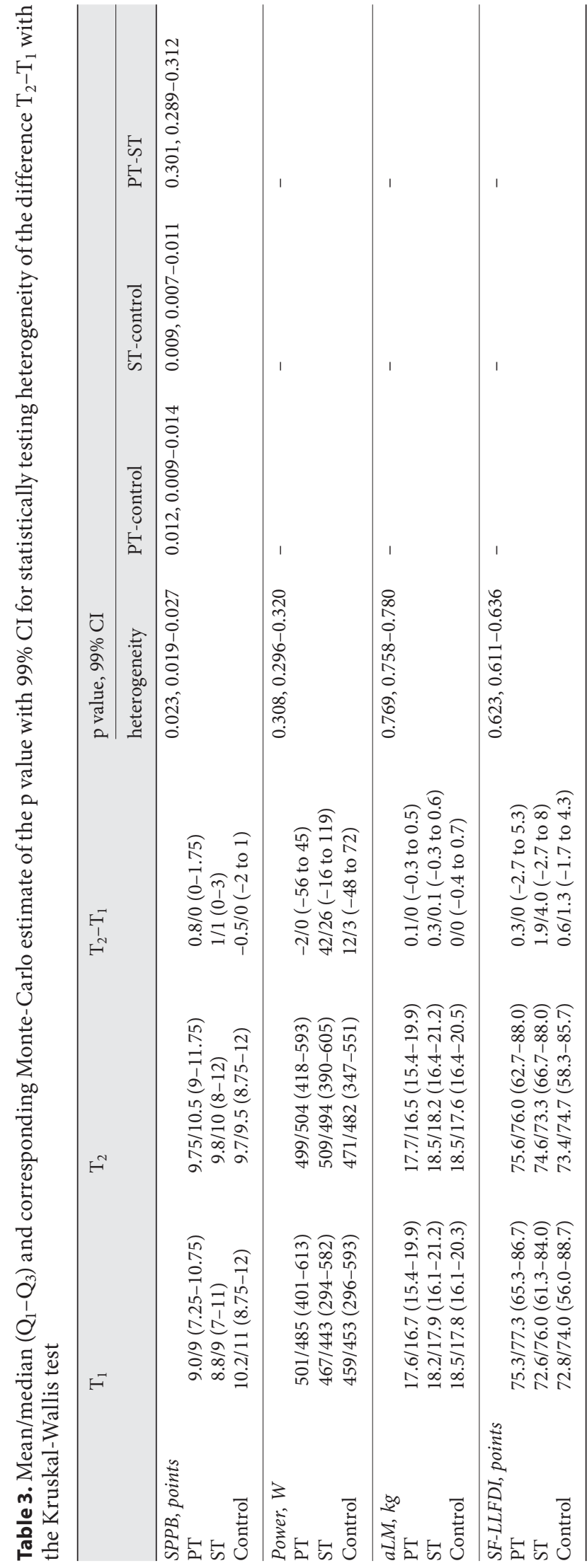

point on the SPPB was accompanied by a significant increase in the 5-year mortality rate [38].

It may be regarded as a shortcoming of the present study that the SPPB was used as an outcome measure as chair rise was both part of the training protocol and part of the SPPB. Therefore, interference in this regard cannot be excluded. To control for this circumstance, a subanalysis excluding chair rise from the SPPB score was performed. In this case, the score ranged from 0 to 8 only including balance and gait only. This sensitivity analysis confirmed the significant findings of the main analysis.

In none of the aforementioned studies was vitamin $\mathrm{D}_{3}$ deficiency accounted for, nor was the outcome controlled for the $25-\mathrm{OH}-\mathrm{D}_{3}$ serum level. Randomized controlled trials in older adults investigating the effects of vitamin D supplementation on physical performance have shown a clear tendency towards improvement in muscle strength and physical performance [15-18]. One rationale for assessing the effects of vitamin D supplementation is that vitamin $\mathrm{D}$ receptors are present in the cell membrane and the core of muscle cells [39]. The genomic effect of vitamin D results in changes in mRNA concentrations and consecutively in de novo protein synthesis in the muscle cell. Nongenomic effects include the activation of protein kinase $\mathrm{C}$, which releases calcium into the cytosol, which is essential for muscle contraction. In the run-in phase of our study, we detected a significant improvement in muscle power and a tendency $(<2 \alpha)$ towards an increase in the SPBB score after vitamin $\mathrm{D}_{3}$ supplementation, although we did not use a control group in this regard. The median of the differences before and after supplementation (table 2) shows only slight improvements in muscle power and SPPB score when compared with the effects of training (table 3). Nevertheless, this finding indicates that vitamin $\mathrm{D}_{3}$ supplementation should become a routine for studies focusing on physical performance in older populations.

In the present study, no difference in muscle power increase was detected between the two training groups. This is in agreement with the findings in 3 of the above mentioned studies $[7,8,13]$. Other authors reported a significantly greater increase in lower extremity muscle power due to PT when compared to ST $[10,12]$. In the 3 studies that showed no differences in muscle power changes between PT and ST, confounding factors, such as length of intervention (10-24 weeks) $[8,10]$, selection of participants (healthy to physically impaired) $[8,10]$ and the methodology applied for measuring muscle power (leg press power for example or anaerobic cycling pow- 
er) $[7,9]$ were not controlled for. One factor that could have had a negative effect on the increase in muscle power in our study might have been the use of the Bodyspider training machine. This machine does not work with weights, but with elastic bands producing the loads. Compared to regular weights, elastic bands lead to different loading characteristics for the working muscles. To perform a powerful movement with regular weights, a high rate of force development and thus an adequate recruitment effect is required, especially at the beginning of the movement. Compared to this, a powerful movement with elastic bands starts with relatively low muscle forces which then have to be increased due to tensioning of the elastic bands during the movement. Nevertheless, as participants had been instructed to perform the explosive movement throughout the range of motion, the different loading characteristics should not interfere with the concept of PT.

In our study, no significant effect was found on aLM. An increase in lean body mass was also absent in $3[8,11$, 13] of the 7 aforementioned studies, where DXA was applied. This evidence supports the hypothesis that the positive effects on physical function in older adults cannot be explained by muscle hypertrophy only, but rather by neurological factors. Training seems to induce neural adaptations, such as increased voluntary activation of agonists and reductions in antagonist coactivation [40]. Rapid motor unit activation and higher firing rates are also discussed as possible mechanisms relevant to the training effects in older individuals [41].
The primary focus of the present study was laid on physical performance. Although improvement in objective physical function was detected, participants did not notice a significant improvement in the self-reported function component of the LLFDI. Nor did Bean et al. [10] find a significant change in the function component of the LLFDI in PT (2.5 points) compared to ST (1.0 points). Unfortunately, data about meaningful changes in the LLFDI have not been established yet.

\section{Conclusion}

In prefrail community-dwelling older persons, $\mathrm{PT}$ does not seem to be superior to ST, although both modes have improved physical performance. Applicability was higher for ST than for PT, as the latter was associated with a higher drop-out rate. The high prevalence of vitamin $\mathrm{D}_{3}$ deficiency and the slight improvement in physical performance by vitamin $\mathrm{D}_{3}$ supplementation underline the relevance of this approach for future trials that focus on physical exercise in older populations.

\section{Acknowledgements}

M.D. and J.M.B. were supported by a Forschungskolleg Geriatrie Grant from the Robert Bosch Foundation, Stuttgart, Germany. The authors would like to thank R. Kaiser for informing the control group on healthy nutrition and C. Hentschke for randomization.

\section{References}

1 Latham NK, Bennett DA, Stretton CM, Anderson CS: Systematic review of progressive resistance strength training in older adults. J Gerontol A Biol Sci Med Sci 2004;59:48-61.

2 Hazell T, Kenno K, Jakobi J: Functional benefit of power training for older adults. J Aging Phys Act 2007;15:349-359.

3 Sayers SP: High-speed power training: a novel approach to resistance training in older men and women. A brief review and pilot study. J Strength Cond Res 2007;21:518-526.

4 Sayers SP, Bean J, Cuoco A, LeBrasseur NK, Jette A, Fielding RA: Changes in function and disability after resistance training: does velocity matter? A pilot study. Am J Phys Med Rehabil 2003;82:605-613.

5 Henwood TR, Taaffe DR: Improved physical performance in older adults undertaking a short-term programme of high-velocity resistance training. Gerontology 2005;51:108115.
6 Orr R, de Vos NJ, Singh NA, Ross DA, Stavrinos TM, Fiatarone-Singh MA: Power training improves balance in healthy older adults. J Gerontol A Biol Sci Med Sci 2006;61: 78-85.

7 Miszko TA, Cress ME, Slade JM, Covey CJ, Agrawal SK, Doerr CE: Effect of strength and power training on physical function in community-dwelling older adults. J Gerontol A Biol Sci Med Sci 2003;58:171-175.

8 Henwood TR, Riek S, Taaffe DR: Strength versus muscle power-specific resistance training in community-dwelling older adults. J Gerontol A Biol Sci Med Sci 2008;63: 83-91.

9 Fielding RA, Le Brasseur NK, Cuoco A, Bean J, Mizer K, Fiatarone Singh MA: High-velocity resistance training increases skeletal muscle peak power in older women. J Am Geriatr Soc 2002;50:655-662.
10 Bean JF, Kiely DK, LaRose S, O’Neill E, Goldstein R, Frontera WR: Increased velocity exercise specific to task training versus the National Institute on Aging's strength training program: changes in limb power and mobility. J Gerontol A Biol Sci Med Sci 2009;64:983-991.

11 Reid KF, Callahan DM, Carabello RJ, Phillips EM, Frontera WR, Fielding RA: Lower extremity power training in elderly subjects with mobility limitations: a randomized controlled trial. Aging Clin Exp Res 2008;20: 337-343.

12 Bottaro M, Machado SN, Nogueira W, Scales $\mathrm{R}$, Veloso J: Effect of high versus low-velocity resistance training on muscular fitness and functional performance in older men. Eur J Appl Physiol 2007;99:257-264. 
13 Marsh AP, Miller ME, Rejeski WJ, Hutton SL, Kritchevsky SB: Lower extremity muscle function after strength or power training in older adults. J Aging Phys Act 2009;17:416443.

14 Tschopp M, Sattelmayer MK, Hilfiker R: Is power training or conventional resistance training better for function in elderly persons? A meta-analysis. Age Ageing 2011;40: 549-556.

15 Bischoff HA, Stähelin HB, Dick W, Akos R, Knecht M, Salis C, Nebiker M, Theiler R, Pfeifer M, Begerow B, Lew RA, Conzelmann M: Effects of vitamin D and calcium supplementation on falls: a randomized controlled trial. J Bone Miner Res 2003;18:343-351.

16 Latham NK, Anderson CS, Reid IR: Effects of vitamin D supplementation on strength, physical performance, and falls in older persons: a systematic review. J Am Geriatr Soc 2003;51:1219-1226.

17 Dhesi JK, Jackson SH, Bearne LM, Moniz C, Hurley MV, Swift CG, Allain TJ: Vitamin D supplementation improves neuromuscular function in older people who fall. Age Ageing 2004;33:589-595.

18 Pfeifer M, Begerow B, Minne HW, Suppan K, Fahrleitner-Pammer A, Dobnig H: Effects of a long-term vitamin $\mathrm{D}$ and calcium supplementation on falls and parameters of muscle function in community-dwelling older individuals. Osteoporos Int 2009;20:315-322.

19 Fried LP, Tangen CM, Walston J, Newman AB, Hirsch C, Gottdiener J, Seeman T, Tracy R, Kop WJ, Burke G, McBurnie MA; Cardiovascular Health Study Collaborative Research Group: Frailty in older adults: evidence for a phenotype. J Gerontol A Biol Sci Med Sci 2001;56:M146-M156.

20 Abellan van Kan G, Rolland Y, Bergman H, Morley JE, Kritchevsky SB, Vellas B: The I.A.N.A. Task Force on frailty assessment of older people in clinical practice. J Nutr Health Aging 2008;12:29-37.

21 Liu CK, Fielding RA: Exercise as an intervention for frailty. Clin Geriatr Med 2011;27: 101-110.

22 Drey M, Pfeifer K, Sieber CC, Bauer JM: The Fried Frailty Criteria as Inclusion Criteria for a Randomized Controlled Trial: Personal Experience and Literature Review. Gerontology 2011;57:11-18.
23 Borg G: Borg's Perceived Exertion and Pain Scales. Champaign, Human Kinetics, 1998.

24 McDermott AY, Mernitz H: Exercise and older patients: prescribing guidelines. Am Fam Physician 2006;74:437-444.

25 Guralnik JM, Simonsick EM, Ferrucci L, Glynn RJ, Berkman LF, Blazer DG, Scherr PA, Wallace RB: A short physical performance battery assessing lower extremity function: association with self-reported disability and prediction of mortality and nursing home admission. J Gerontol 1994; 49:M85-M94.

26 Guralnik JM, Ferrucci L, Simonsick EM, Salive ME, Wallace RB: Lower-extremity function in persons over the age of 70 years as a predictor of subsequent disability. $\mathrm{N}$ Engl J Med 1995;332:556-561.

27 Guralnik JM, Ferrucci L, Pieper CF, Leveille SG, Markides KS, Ostir GV, Studenski S, Berkman LF, Wallace RB: Lower extremity function and subsequent disability: consistency across studies, predictive models, and value of gait speed alone compared with the short physical performance battery. J Gerontol A Biol Sci Med Sci 2000;55:M221-M231.

28 Lindemann U, Claus H, Stuber M, Augat P, Muche R, Nikolaus T, Becker C: Measuring power during the sit-to-stand transfer. Eur J Appl Physiol 2003;89:466-470.

29 Denkinger MD, Igl W, Coll-Planas L, Bleicher J, Nikolaus T, Jamour M: Evaluation of the short form of the late-life function and disability instrument in geriatric inpatients - validity, responsiveness, and sensitivity to change. J Am Geriatr Soc 2009;57:309-314

30 Haley SM, Jette AM, Coster WJ, Kooyoomjian JT, Levenson S, Heeren T, Ashba J: Late Life Function and Disability Instrument. II. Development and evaluation of the function component. J Gerontol A Biol Sci Med Sci 2002;57:M217-M222.

31 Sayers SP, Jette AM, Haley SM, Heeren TC, Guralnik JM, Fielding RA: Validation of the Late-Life Function and Disability Instrument. J Am Geriatr Soc 2004;52:1554-1559.

32 Bean JF, Leveille SG, Kiely DK, Bandinelli S, Guralnik JM, Ferrucci L: A comparison of leg power and leg strength within the InCHIANTI study: which influences mobility more? J Gerontol A Biol Sci Med Sci 2003; 58:728-733.
33 Foldvari M, Clark M, Laviolette LC, Bernstein MA, Kaliton D, Castaneda C, Pu CT, Hausdorff JM, Fielding RA, Singh MA: Association of muscle power with functional status in community-dwelling elderly women. J Gerontol A Biol Sci Med Sci 2000; 55:M192-M199.

34 Porter MM: Power training for older adults. Appl Physiol Nutr Metab 2006;31:87-94.

35 Bean JF, Kiely DK, LaRose S, Goldstein R, Frontera WR, Leveille SG: Are changes in leg power responsible for clinically meaningful improvements in mobility in older adults? J Am Geriatr Soc 2010;58:2363-2368.

36 Perera S, Mody SH, Woodman RC, Studenski SA: Meaningful change and responsiveness in common physical performance measures in older adults. J Am Geriatr Soc 2006; 54:743-749.

37 Kwon S, Perera S, Pahor M, Katula JA, King AC, Groessl EJ, Studenski SA: What is a meaningful change in physical performance? Findings from a clinical trial in older adults (the LIFE-P study). J Nutr Health Aging 2009;13:538-544.

38 Perera S, Studenski S, Chandler JM, Guralnik JM: Magnitude and patterns of decline in health and function in 1 year affect subsequent 5-year survival. J Gerontol A Biol Sci Med Sci 2005;60:894-900.

39 Montero-Odasso M, Duque G: Vitamin D in the aging musculoskeletal system: an authentic strength preserving hormone. Mol Aspects Med 2005;26:203-219.

40 Häkkinen K, Kraemer WJ, Newton RU, Alen M: Changes in electromyographic activity, muscle fibre and force production characteristics during heavy resistance/power strength training in middle-aged and older men and women. Acta Physiol Scand 2001; 171:51-62.

41 Macaluso A, De Vito G: Muscle strength, power and adaptations to resistance training in older people. Eur J Appl Physiol 2004;91: $450-472$. 